\title{
Are endophytes an important link between airborne spores and allergen exposure?
}

Beatriz R. Vázquez de Aldana ${ }^{1}$, Gerald Bills ${ }^{2}$, Iñigo Zabalgogeazcoa ${ }^{1}$

1 Instituto de Recursos Naturales y Agrobiología de Salamanca (IRNASA-CSIC); Cordel de Merinas 4052, 37008 Salamanca, Spain

2. University of Texas Health Science Center at Houston; Texas Therapeutics Institute; The Brown Foundation Institute for Molecular Medicine; 1825 Pressler Street, Houston, Texas 77030, USA

Corresponding author:

Iñigo Zabalgogeazcoa

Email: i.zabalgo@irnasa.csic.es

Telephone: +34923219606

Fax: +34 923219609

Fungal Diversity 2013 (DOI) 10.1007/s13225-013-0223-z 


\begin{abstract}
Grasses represent one of the Earth's most common plant groups, and natural and cultivated habitats dominated by grasses cover about $40 \%$ of the land surface. In turn, each grass species hosts multiple fungal species which can behave as endophytes. An analysis of the endophytic taxa identified in surveys conducted in 14 grass species showed that some of the most frequent taxa on each grass were also present across several host grasses. These taxa were Alternaria, Epicoccum, Cladosporium, Fusarium, and a few others. A similar analysis of airborne fungi surveyed at 41 different locations throughout the world showed that some of the most geographically widespread, and most locally frequent airborne fungi belonged to the same genera that are dominant endophytes in grasses (i.e. Cladosporium, Alternaria, Fusarium, etc.). Therefore, airborne spores of genera that are ubiquitous in grasses are common worldwide and attain high atmospheric concentrations. In addition, spores of the above mentioned fungi are also important respiratory allergens. Direct observation indicates that saprobic colonization and sporulation of non-systemic grass endophytes could become unrestrained when their host plant tissue dies. Subsequently, when appropriate environmental conditions favour sporulation on grass host surfaces, the natural cycle for airborne conidia initiates, and large numbers of these conidia disperse as inoculum for new endophytic infections. Therefore, the cycle of endophytism may be an important link between climate, plant biology and public health.
\end{abstract}

Keywords: grasses, airborne spores, endophytes, Cladosporium, Alternaria, Fusarium, Epicoccum 


\section{Introduction}

Grasses comprise one of the most successful plant families on Earth. The approximately 11000 species of the Poaceae are distributed from polar to tropical latitudes, and grass-dominated habitats, like grasslands, represent about $40 \%$ of the land surface. In the atmosphere, usually more than $25 \%$ of the airborne pollen grains belong to grasses, and in cultivated land, grasses are the most important crops (Strömberg 2011).

In turn, grasses host a very diverse and rich assemblage of endophytic fungi, capable of infecting plant tissues without causing symptoms for most or all of the plant's lifespan (Hyde and Soytong 2008; Rodriguez et al. 2009; Sánchez et al. 2012). Hundreds of species of grass endophytes have been identified in surveys that produced non asymptotic species accumulation curves, indicating that the richness of these mycobiotas was underestimated (Higgins et al. 2011; Sanchez et al. 2012). The endophytic assemblages of grasses, and also of other plants, are usually dominated by a few fungal species having a relatively high prevalence within host populations. Some of the dominant endophytic taxa in grasses are Alternaria, Cladosporium, Penicillium and Fusarium (Table 1 references; Stone et al. 2004; Ghimire et al. 2011; Sánchez et al. 2012). Given their ubiquity in grasses, dominant endophytes such as these must produce large quantities of inoculum, facilitating their transmission to new hosts. However, little is known about when and under which circumstances these endophytic species sporulate.

Although there are exceptions, like the Epichloë species which infect systemically the aerial tissues of their hosts and are seed transmitted, most endophytic fungi in grasses and other plant taxa infect locally host tissues and have horizontal transmission (Saikkonen et al. 1998; Clay and Schardl 2002; Rodriguez et al. 2009). The growth of these non-systemic endophytes is limited in the host plant in what has been hypothesized to be a situation of "balanced antagonism", where fungal growth is restricted, but not to the point where plant defense mechanisms can eliminate the fungus (Schulz and Boyle 2005).

The completion of the life cycle of non-systemic endophytic species requires sporulation, but this is not likely to occur during an endophytic phase because infections occur in healthy tissues. Sporulation of endophytes could occur in several different scenarios. One possibility is that some endophytes might be latent pathogens that will sporulate in diseased plant tissue. However, pathogens are not a considerable fraction of the endophytic mycobiota of plants, for example, only $15 \%$ of the endophytic species identified in Dactylis glomerata were known pathogens of this grass (Stone et al. 2004; Sánchez et al. 2007). Another possibility is that some endophytes may be latent saprobes capable of switching to a saprobic lifestyle after host tissue death, and then grow unrestricted on their host and sporulate. Several studies support this possible scenario (Sieber Canavesi and Sieber 1993; Bills and Pelaez 1996; Müller et al. 2001; Cannon and Sutton, 2004; Osono 2006; Promputtha et al. 2007; Parfitt et al. 2010; Purahong and Hyde 2011; Sánchez et al. 2011; Sun et al. 2011; Bills et al. 2012).

While studying the diversity of the endophytic mycobiota of grasses in Spain (Sánchez et al. $2007 ; 2008 ; 2010 ; 2012$ ), we noticed that some of the most common grass endophytes belong to taxa whose spores have been reported as particle components of the air. Given the abundance of grasses on 
earth, and their frequent association with endophytic taxa whose spores are also found in the atmosphere, we hypothesized that if dominant endophytic species would produce spores when their host tissue dies, then grass endophytism could be an important source of airborne spores. This sequence would not only represent an important biological cycle affecting plant decomposition and fungal reproduction, but also a potential intervention point for reducing airborne allergen load. To substantiate this hypothesis, we reviewed surveys of the endophytic mycobiota of grasses and of airborne mycobiota, identifying the most prevalent endophytic taxa on each substratum.

\section{Dominant endophytic taxa in grasses}

Data was obtained from 15 surveys of fungal endophytes isolated from the aerial organs of 14 different grass species (Table 1). In each survey, the frequency of each reported endophyte was estimated as its number of isolates divided by the total number of fungal isolates reported in that survey. This frequency was expressed as a percentage of the total mycobiota. Only genera representing more than $1 \%$ of the total mycobiota of their hosts were considered.

The mean frequency of each endophytic genus in its hosts was estimated as the sum of its frequencies in all grasses where it was reported, divided by the number of host grasses. The total or global frequency in grasses of each endophytic taxon was estimated as the sum of its frequencies on all hosts, divided by 14, the total number of grass species considered. Pearson's product moment correlation ( $r$ ) was used to assess the strength of the relationships between variables like mean frequency per host and number of host grass species.

The analysis of endophyte abundance in the set of 14 grass species allowed the identification of the most common genera occurring in this set of grasses. Sixty two different fungal genera, each one representing more than $1 \%$ of all endophyte isolates obtained in each survey, occurred in the whole set of grasses. Thirty of these genera were reported in more than one host species (Fig. 1), and Epicoccum, Cladosporium, Alternaria, Fusarium and Acremonium occurred in more than half of the grass species analyzed. Alternaria was the most frequent endophytic taxon among the selected hosts, on average $22.0 \%$ of the endophytes isolated from leaves of host species belonged to this genus. This genus also showed a high multihost capability, being reported in 13 of the 14 host species analysed. Epicoccum and Cladosporium also occurred in 13 out of 14 grass species; but they were less frequent than Alternaria in their hosts (Fig. 1).

Considering the set of endophytes listed in Fig. 1, taxa with a high multihost capability tended to have a high frequency in their hosts $(r=0.59 ; n=30, P<0.01)$. This positive significant correlation suggests that more host-generalist endophytes tend to have a greater prevalence in their respective hosts than endophytes that are more host-specific. It is likely that these endophytic taxa have very efficient mechanisms for propagation, to infect hosts, and to evade plant defense mechanisms.

In a given environment, the total abundance of an endophyte will depend on its abundance in host populations, and on the number of host species that it infects. An estimation of the total frequency of each endophyte in the whole grass set (Fig. 2) showed that some endophytes having high mean 
frequencies in their hosts, had a low total frequency in grasses due to their limited host range (i.e. Periconia, Stagonospora, Sporormiella). From a global point of view, Alternaria, Epicoccum, Cladosporium, Fusarium and Acremonium were the most frequent genera. These genera were often among the most prevalent in each survey; for instance, Alternaria was one of the three most frequent fungi in all the hosts where it was reported, and Cladosporium, was one of the three most frequent in $31 \%$ of the grasses where it was reported as an endophyte.

In conclusion, an analysis of endophyte surveys helped to identify fungal taxa achieving a high prevalence among different host grass populations, as well as multihost taxa present in several grass species. Some of the most abundant endophytes were also those with the greatest multihost capability, this is the case of Alternaria, Epicoccum, Cladosporium, Fusarium and Acremonium. Therefore, considering the abundance of grasses on earth, and the apparently ubiquitous relationships of these fungi with grasses, these endophyte taxa can be considered important organisms in grass dominated ecosystems. Furthermore, some of these fungal genera have also been reported as dominant endophytes in leaves of dicotyledonous plant species, like Arabidopsis thaliana (García et al. 2012), Vitis vinifera (González and Tello 2011), Cirsum arvense, Plantago lanceolata, Rumex acetosa (Wearn et al. 2012), and others.

Relative to other plant families, many species of the Poaceae have been surveyed for endophytes; therefore, some common patterns can be discerned. Nevertheless, dominant endophytes occurring in grasses could also predominate in other plant families. However, in conifers, genera like Lophodermium seem to be the dominant multihost endophytes, and the above mentioned endophytes, although in some cases were present, they were not as prevalent (Müller et al. 2001; Arnold et al. 2007; Sieber 2007; Yuan et al. 2011; Botella and Díez 2011; Koukol et al. 2012).

\section{Airborne mycobiota}

Most surveys of airborne fungi are based on methods where spores are trapped by air sampling devices, and afterwards the spores or the cultures to which they give rise, are identified. To identify the main taxa of airborne fungi and to estimate their abundance, we used data provided by 33 surveys of outdoor airborne fungi, carried out at 41 locations in different continents, countries and habitats (Table 2). Survey locations were defined as urban $(n=21)$, inside cities, and rural habitats $(n=20)$ which included croplands, grasslands, forests and large city parks. For each fungal airborne genus, its frequency at each location (local abundance) was estimated based on its number of samples or propagules (i.e. cfu $\mathrm{m}^{-3}$, number of isolates) relative to the total number of airborne fungal samples recorded at that location. Only the fungal taxa representing more than $1 \%$ of the propagules of the total aerial mycobiota at any location were considered. The mean frequency per location of each fungal taxon was estimated as the mean of all locations where it was reported. The global frequency of each airborne fungal species was estimated as the sum of its frequencies at each location where it occurred, divided by 41 , the total number of locations. This estimate is related to the spore abundance of a given genus at a random location. 
A set of 67 fungal genera resulted from an analysis of the whole set of surveys (Table 2). Thirty five of these genera occurred at more than one location and were considered for the subsequent analyses (Fig. 3). In terms of presence at different geographical locations, Cladosporium spores were ubiquitous, being recorded at $95 \%$ of the locations analyzed; Alternaria, Aspergillus and Penicillium were found at $65-89 \%$ of the locations, and Fusarium and Epicoccum were found at $25-35 \%$ of the locations (Fig. 3). In terms of local frequency, Cladosporium was the dominant taxon, representing an average of $40 \%$ of the spores detected at each location (Fig. 3). Other taxa that were detected at few locations, like Aureobasidium and Geotrichum, had high local frequency (21\%). However, a significant correlation between the local frequency and the number of locations where each genus was found $(r=0.64 ; n=35$; $P<0.001$ ), indicated that fungi having a high local frequency tend to be geographically widespread. We did not detect any noticeable difference in the most abundant genera between urban and rural habitats (data not shown).

When observed from the perspective of global abundance, Cladosporium stands out as an extremely abundant and geographically widespread fungus, representing about $40 \%$ of the airborne spores recorded at any location. This taxon was followed distantly by Penicillium, Alternaria and Aspergillus with global frequency values around $12 \%$ (Fig. 4). The remaining taxa had very low global abundance values, below $3 \%$.

Airborne spore concentrations and their diversity vary with the time of day, season of the year, geographical region, air pollution, meteorological parameters, presence of local sources, and vegetation types. Our review was based on surveys done at 41 locations around the world, including different climate regions to achieve the highest variability possible. Thus, we found that the most widespread airborne fungi were also the most frequent (Cladosporium, Penicilium, Alternaria and Aspergillus). This implies that in spite of all of the above factors of variation, these fungal taxa are ubiquitous in the Earth's atmosphere.

\section{Are grasses an important source of airborne spores?}

Seventeen of the 30 endophytic genera most common in grasses (Fig. 2) were also present in the list of common airborne genera (Fig. 4). These fungi showing endophytic and airborne phases in their life cycles are Acremonium, Alternaria, Aureobasidium, Chaetomium, Cladosporium, Curvularia, Drechslera, Epicoccum, Fusarium, Leptosphaeria, Nigrospora, Penicillium, Periconia, Phoma, Pleospora, Trichoderma and Ulocladium. In this set of fungi, a trend for increasing multihost capability with increasing frequency in the air was apparent $(r=0.72 ; n=17 ; P<0.01)$, and particularly evident in Cladosporium, Alternaria, Penicillium, Fusarium, and Epicoccum (Fig. 5). These five genera also happened to be some of the most frequent endophytes in grasses and airborne fungi (Figs. 2 and 4). This very interesting coincidence suggests that grasses are an important source of airborne fungi, and leads one to consider whether these dominant grass endophytes may produce at some time of their life cycle spores that become airborne. 
One condition contributing to endophyte sporulation is the senescence or death of their host tissue, because some host-imposed constraints on endophyte growth disappear. A switch from an endophytic to a saprobic lifestyle seems to occur in many fungal species (Stone et al. 2004; Hyde and Soytong 2008). Several studies have provided evidence of this transition where endophytes become saprobes in senescent or dead tissue of their host plants (Sieber Canavesi and Sieber 1993; Bills and Pelaez 1996; Müller et al. 2001; Cannon and Sutton 2004; Osono 2006; Promputtha et al. 2007; Parfitt et al. 2010; Purahong and Hyde 2011; Sánchez et al. 2011; Sun et al. 2011; Bills et al. 2012). In grasses like Dactylis glomerata, Lolium perenne and bamboo, spore bearing structures of Cladosporium, Epicoccum, Alternaria, Phaeosphaeria and other endophytic taxa have been observed in the early phases of leaf and stem senescence, as well as in dead stems (Webster 1956; Brown 1984; Thomas and Shattock 1986; Wong and Hyde 2001; Zhou and Hyde 2002; Sánchez et al. 2007). In addition, we have observed that after placing surface disinfected fragments of field collected grasses of different species in moist chambers without artificial growth medium, conidia and conidiophores of Alternaria and other fungi developed on leaf surfaces (not published). The above observations strongly indicate that some grass endophytes, among them dominant taxa, can sporulate on dead host surfaces. Furthermore, growth and reproduction of endophytes after the death of their host tissue fits well within the theory of balanced antagonism (Schultz and Boyle 2005). Host tissue death would release host-imposed constraints for fungal growth in endophytes able to switch to a saprobic lifestyle.

A transition from an endophytic to a saprobic phase is likely to bring important changes in the fungus that might allow more mycelial growth and the development of reproductive structures. In this sense, Abdellatif et al. (2009) showed that the morphology of endophytic hyphae, as well as the patterns of root colonization change remarkably in living or dead wheat roots; and several endophytic species, including Alternaria and Epicoccum are known to produce several cell wall degrading enzymes in vitro or when growing as a saprotrophs (Brown 1984; Sun et al. 2011). Nevertheless, fungi like Alternaria, Cladosporium, Epicoccum, Fusarium and Penicillium often occur as saprobes (Richards 1953; Brown 1984; Fracchia et al. 2000; Thomma 2003; Bills et al. 2004), and they might also colonize other dead substrata besides their previous plant hosts, obviating an endophytic phase in their life cycle.

Based on the above evidence, some grass-associated endophytic genera like Alternaria, Cladosporium, Epicoccum, Fusarium, and others might have a life cycle as follows (Fig. 6): 1) These fungi have an endophytic lifestyle in grasses and other plants, having their growth restricted in living hosts. 2) When the plant host tissue dies, the endophytes can grow in the dead tissue as saprobes or remain latent and viable. 3) Given the appropriate environmental conditions (i.e. humidity, temperature) these fungi can grow and sporulate, often over extensive areas of the plant surface, and finally releasing spores to the atmosphere. The seasonality of sporulation observed in taxa like Alternaria, Cladosporium, Penicillium, and others support this hypothesis (i.e. Garrett et al. 1997; Henriquez et al. 2001; Stennett et al. 2004; Pyrri et al. 2007; Oliveira et al. 2009). The spores of these fungi achieve their highest aerial concentrations in the spring and/or fall at locations where rains and mild temperatures, adequate for fungal growth, occur in these seasons. 4) As a result, a huge number of spores produced in dead plant 
tissue become airborne, and their deposition on live plant tissues represent the inoculum for horizontally transmitted endophytes. These spores might also colonize decaying or newly dead plant tissue.

To test this hypothesis that grass endophytes contribute significantly to airborne spores, further studies are needed. Research aimed at defining species and population level genetic markers in endophytes of genera such as Alternaria and Cladosporium, and tracking these markers between endophytic and airborne populations will help to determine if species from each substratum are different, or if endophytes are a specific subpopulation among the airborne spores. Studies documenting the continuity of phases in the life cycles of endophytes in grasses will help to support the hypothesis of their sporulation when their host tissue dies, to assess the contribution of endophytes to plant decomposition (i.e. Omacini et al. 2004; Purahong and Hyde 2011; Sun et al. 2011), and to obtain estimates of the amount of spores produced and released to the air per unit of dead plant tissue. Finally, knowledge about the mechanisms that restrict the growth of endophytes in living tissues will be helpful to understand the endophyte-saprobe transition, and might have interesting applications in plant pathology and plant breeding.

\section{Biological relevance of an endophytic-saprophytic-airborne cycle}

Grasses are very successful plants: thousands of species are distributed throughout many different and contrasting terrestrial habitats, including a major part of the agricultural land. In turn, these grasses are habitats occupied by numerous species of endophytic fungi. In the grass landscape, endophytes belonging to species of Alternaria, Cladosporium, Epicoccum, Fusarium, and other genera (Fig. 2) seem to be ubiquitous. After a transition from an endophytic to a saprobic lifestyle, these fungi are likely to play a very important role in nutrient cycling as plant decomposers, as they use nutrients from the dead tissue of their hosts for mycelial growth and sporulation. A similar situation has been reported in trees, where fungal species previously known as dead wood decomposers were found to preexist as endophytes in living trees (Parfitt et al. 2010).

The sporulation of dominant grass endophytes on dead plant matter, either on previous endophyte hosts or in new substrata, amplify these fungi into extremely abundant life forms. Some estimations of the Alternaria spore concentration in the air range from 10 to 153 spores $\mathrm{m}^{-3}$ (Ulevicius et al. 2004; Sautour et al. 2009). Based on these figures, and if the polar circles are excluded from calculations, in the lower $10 \mathrm{~m}$ of the biosphere we would expect to find $2 \cdot 10^{16}$ to $2 \cdot 10^{17}$ spores of this taxon. Much larger figures should be expected for Cladosporium, the most prevalent airborne taxon.

Another impact of this work is the link with human respiratory allergies. Common respiratory allergy symptoms, such as asthma and rhinitis, can often be a result of exposure to airborne fungi. The main allergens found in outdoor environments are pollen grains and fungal spores, whose concentration might be 100 - to 1000 -fold that of pollen grains, depending on environmental factors affecting plant and fungal growth (Horner et al. 1995). It has been estimated that about $5 \%$ of the general population will suffer at some time an allergy caused by fungi, and about $20-30 \%$ of the patients suffering from respiratory allergy are sensitized to fungal spores (Kurup et al. 2000; Gioleukas et al. 2004; Bush et al. 
2006). Outdoor exposure seems to be more important than indoor exposure for sensitization to fungal spores, and several studies have shown that the most common airborne genera were found both indoors and outdoors, although outdoor fungal spore concentrations tend to be greater or similar than indoor (Garrett et al. 1997; Lee et al. 2006; Gonzalvez et al. 2010). Not all spores are allergenic, but spores of genera like Alternaria, Aspergillus, Cladosporium or Fusarium are among the most important allergens, often linked to asthma and rhinitis (Horner et al. 1995; Kurup et al. 2000; Bush et al. 2006; Pulimood et al. 2007). Other allergenic spores are also endophytes in fact, 11 out of 24 fungal genera listed as frequently associated with allergy by Kurup et al. (2000) are also grass endophytes: Alternaria, Aureobasidium, Cladosporium, Curvularia, Drechslera, Fusarium, Penicillium, Phoma, Trichoderma, Ulocladium, and Epicoccum. Therefore, grasses can be a source of spores of allergenic fungal species, and the knowledge of this situation might be useful to prevent fungal allergies in some environments.

Climate change might affect the future distribution of grasses in some parts of the world. For instance, the predicted reduction in rainfall and increase in temperature in southern Europe may favour grasslands in the grassland-forest equilibrium, because of an increased risk of fires, and also the expansion of heat tolerant $\mathrm{C}_{4}$ grasses. In addition, increased plant growing seasons in northern Europe might result in more grass biomass production ('t Mannetje 2007). Thus, climate trends affecting grass growth and distribution might result in increased production of grass tissue available for endophytes, that in turn will sporulate in dead hosts. This could be a factor having an impact in respiratory allergies and other animal diseases caused by fungi (García Solache and Casadevall 2010).

In conclusion, some of the most the abundant spores found in the atmosphere have the capability to interact with plants, where they may become endophytes first and saprobes later. These fungi are extremely abundant as endophytes in grasses and other plant taxa, and are likely to have important roles as saprobes, in plant decomposition and nutrient cycling. Furthermore, the spores of these fungi also interact with human immune systems, being respiratory allergens. Fungi might have had an important impact in the evolution of land animals, as a force of selection for homeothermy (Casadevall 2012), and given the ubiquity and abundance of some important allergenic spores in the atmosphere, these spores might be currently having an impact in the evolution of immune responses to respiratory allergens.

\section{Acknowledgements}

This work was funded by Project AGL2011-22783, granted by the Spanish Government. We thank members of COST Action FA1103 and Dr. Noemi Herrero for help discussing the contents of this paper.

\section{References}

Abdellatif L, Bouzid S, Kaminskyj S, Vujanovic V (2009) Endophytic hyphal compartmentalization is required for successful symbiotic Ascomycota association with root cells. Mycol Res 113:782-791 
Abdel Hameed AA, Khoder MI, Emad AA (2007) Fertile fungal spores collected on different faced surfaces in the atmosphere of Giza, Egypt. Aerobiologia 23:47-57

Abdul Wahid OA, Moustafa AWF, Moustafa AM (1996) Fungal population in the atmosphere of Ismailia City. Aerobiologia 12:249-255

Abu-Dieyeh MH, Barham R, Abu-Elteen K, Al-Rashidi R, Shaheen I (2010) Seasonal variation of fungal spore populations in the atmosphere of Zarqa area, Jordan. Aerobiologia 26:263-276

Airaudi D, Marchisio VF (1996) Fungal biodiversity in the air of Turin. Mycopathologia 136:95-102

Al-Subai AAT (2002) Air-borne fungi at Doha, Qatar. Aerobiologia 18:175-183

Al-Suwaine AS, Hasnain SM, Bahkali AH (1999) Viable airborne fungi in Riyadh, Saudi Arabia. Aerobiologia 15:121-130

Arnold AE, Henk DA, Eells RL, Lutzoni F, Vilgalys R (2007) Diversity and phylogenetic affinities of foliar fungal endophytes in loblolly pine inferred by culturing and environmental PCR. Mycologia 99:185-206

Awad AHA (2005) Vegetation: A source of air fungal bio-contaminant. Aerobiologia 21:53-61

Bills GF, Peláez F (1996) Endophytic isolates of Creosphaeria sassafras. Mycotaxon 57:471-477

Bills GF, Christensen M, Powell M, Thorn G (2004). Saprobic soil fungi. In: Mueller GM, Bills GF, Foster MS (eds) Biodiversity of fungi. Inventory and monitoring methods. Elsevier Academic Press, USA, pp 271-302

Bills GF, González V, Platas G (2012) Kabatiella bupleuri sp. nov. (Dothideales), a pleomorphic epiphyte and endophyte of the Mediterranean plant Bupleurum gibraltarium (Apiaceae). Mycologia 104:962-973

Botella L, Díez J (2011) Phylogenic diversity of fungal endophytes in Spanish stands of Pinus halepensis. Fungal Divers 47:9-18

Brown AB (1984) Epicoccum nigrum, a primary saprophyte involved in the retting of flax. Trans Brit Mycol Soc 83: 29-35

Bush RK, Portnoy JM, Saxon A, Terr Al, Wood RA (2006) The medical effects of mold exposure. J Allergy Clin Immun 117:326-333

Calderón C, Lacey J, McCartney A, Rosas I (1997) Influence of urban climate upon distribution of airborne deuteromycete spore concentrations in Mexico City. Int J Biometeorol 40:71-80

Cannon PF, Sutton BC (2004) Microfungi on wood and plant debris. In: Mueller, GM, Bills, GF, Foster, MS (eds), Biodiversity of Fungi. Inventory and Monitoring Methods. Elsevier Academic Press, USA, pp. 217-239

Casadevall A. 2012. Fungi and the rise of mammals. PLOS Pathogens 8:e1002808.

Clay K, Schardl C (2002) Evolutionary origins and ecological consequences of endophyte symbiosis with grasses. Am Nat 160S: 99-127

Dransfield M (1966) The fungal air-spora at Samaru, Northern Nigeria. Trans British Mycol Soc 49:121132 
Fang Z, Ouyang Z, Hu L, Wang X, Zheng H, Lin X (2005) Culturable airborne fungi in outdoor environments in Beijing, China. Sci Total Environ 350:47-58

Fisher PJ, Petrini O (1992) Fungal saprobes and pathogens as endophytes of rice (Oryza sativa L.). New Phytol 120:137-143

Fisher PJ, Petrini O, Lappin Scott HM (1992) The distribution of some fungal and bacterial endophytes in maize (Zea mays L.). New Phytol 122: 299-305

Fracchia S, Garcia-Romera I, Godeas A, Ocampo JA (2000) Effect of the saprophytic fungus Fusarium oxysporum on arbuscular mycorrhizal colonization and growth of plants in greenhouse and field trials Plant Soil 223:175-184

García E, Alonso A, Platas G' Sacristán S (2012) The endophytic mycobiota of Arabidopsis thaliana Fungal Divers (in press) doi:10.1007/s13225-012-0219-0

García Solache MA, Casadevall A (2010) Hypothesis. Global warming will bring new fungal diseases for mammals. mBIO1(1)e00061-10

Garrett M, Hooper B, Cole F, Hooper M (1997) Airborne fungal spores in 80 homes in the Latrobe Valley, Australia: levels, seasonality and indoor-outdoor relationship. Aerobiologia 13:121-126

Ghimire SR, Charlton ND, Bell JD, Krishnamurthy YL, Craven KD (2011) Biodiversity of fungal endophyte communities inhabiting switchgrass (Panicum virgatum L.) growing in the native tallgrass prairie of northern Oklahoma. Fungal Divers 47:19-27.

Gioulekas D, Damialis A, Papakosta D, Spieksma F, Giouleka P, Patakas D (2004) Allergenic fungi spore records (15 years) and sensitization in patients with respiratory allergy in Thessaloniki- Greece. J Invest Allerg Clin Immunol 14:225-231

González V, Tello ML (2011)The endophytic mycota associated with Vitis vinifera in central Spain. Fungal Divers 47:29-42

Gonzalves FLT, Bauer H, Cardoso MRA, Pukinskas S, Matos D, Melhem M, Puxbaum H (2010) Indoor and outdoor atmospheric fungal spores in the Sao Paulo metropolitan area (Brazil): Species and numeric concentrations. Int J Biometeorol 54:347-355

Henriquez VI, Villegas GR, Nolla JMR (2001) Airborne fungi monitoring in Santiago, Chile. Aerobiologia $17: 137-142$

Herrero AD, Ruiz SS, Bustillo MG, Morales PC (2006) Study of airborne fungal spores in Madrid, Spain. Aerobiologia 22:135-142

Higgins KL, Coley PD, Kursar TA, Arnold AE (2011) Culturing and direct PCR suggest prevalent host generalism among diverse fungal endophytes of tropical forest grasses. Mycologia 103:247-260

Horner WE, Helbling A, Salvaggio JE, Lehrer SB (1995) Fungal allergens. Clin Microbiol Rev 8:161-179

Hyde KD, Soytong K (2008) The fungal endophyte dilemma. Fungal Divers 33: 163-173

Ismail MA, Chebon SK, Nakamya R (1999) Preliminary surveys of outdoor and indoor aeromycobiota in Uganda. Mycopathologia 148:41-51

Kasprzyk I, Worek M (2006) Airborne fungal spores in urban and rural environments in Poland. Aerobiologia 22:169-176 
Kleczewski NM, Bauer JT, Bever JD, Clay K, Reynolds HL (2012) A survey of endophytic fungi of switchgrass (Panicum virgatum) in the Midwest, and their putative roles in plant growth. Fungal Ecol 5:521-529

Koukol O, Kolařík M, Kolářová Z, Baldrian P (2012) Diversity of foliar endophytes in wind-fallen Picea abies trees. Fungal Diversity 54:69-77

Kurup VP, Shen HD, Banerjee B (2000) Respiratory fungal allergy. Microbes Infect 2:1101-1110

Lee T, Grinshpun SA, Martuzevicius D, Adhikari A, Crawford CM, Reponen T (2006) Culturability and concentration of indoor and outdoor airborne fungi in six single-family homes. Atmos Environ 40:29022910

Li DW, Kendrick B (1995) A year-round study on functional relationships of airborne fungi with meteorological factors. Int J Biometeorol 39:74-80

Lim SH, Chew FT, Dali SDBM, Tan HTW, Lee BW, Tan TK (1998) Outdoor airborne fungal spores in Singapore. Grana 37:246-252

Lugauskas A, Sveistyte L, Ulevicius V (2003) Concentration and species diversity of airborne fungi near busy streets in Lithuanian urban areas. Ann Agric Env Med 10:233-239

Magyar D, Frenguelli G, Bricchi E, Tedeschini E, Csontos P, Li DW, Bobvos J (2009) The biodiversity of air spora in an Italian vineyard. Aerobiologia 25:99-109

Mallo AC, Nitiu DS, Gardella Sambeth MC (2011) Airborne fungal spore content in the atmosphere of the city of La Plata, Argentina. Aerobiologia 27:77-84

't Mannetje L (2007) Climate change and grasslands through the ages: an overview. Grass Forage Sci 62:113-117

Mitakakis TZ, Guest DI (2001) A fungal spore calendar for the atmosphere of Melbourne, Australia, for the year 1993. Aerobiologia 17:171-176

Moustafa AF, Kamel SM (1976) A study of fungal spore populations in the atmosphere of Kuwait. Mycopathologia 59:29-35

Müller MM, Valjakka R, Suokko A, Hantula J (2001) Diversity of endophytic fungi of Norway spruce needles and their role as pioneer decomposers. Mol Ecol 10:1801-1810

Muñoz Rodriguez AF, Palacios IS, Molina RT, Bernabe JAR (2010) Distribution of airborne fungal propagule concentrations in an irrigated cropland zone. J Phytopathol 158:513-522

Nayar TS, Mohan TK, Jothish PS (2007) Status of airborne spores and pollen in a coir factory in Kerala, India. Aerobiologia 23:131-143

Oliveira M, Ribeiro H, Delgado JL, Abreu I (2009) The effects of meteorological factors on airborne fungal spore concentration in two areas differing in urbanisation level. Int J Biometeorol 53:61-73

Omacini M, Chaneton EJ, Ghersa CM, Otero P (2004) Do foliar endophytes affect grass litter decomposition? A microcosm approach using Lolium multiflorum. Oikos 104:581-590

Osono T (2006) Role of phyllosphere fungi of forest trees in the development of decomposer fungal communities and decomposition processes of leaf litter. Can J Microbiol 52:701-716 
Pan JJ, Baumgarten AM, May G (2008) Effects of host plant environment and Ustilago maydis infection on the fungal endophyte community of maize (Zea mays). New Phytol 178:147-156

Parfitt D, Hunt J, Dockrell D, Rogers HJ, Boddy L (2010) Do all trees carry the seeds of their own destruction? PCR reveals numerous wood decay fungi latently present in sapwood of a wide range of angiosperm trees. Fungal Ecol 3:338-346

Peláez F, Collado J, Arenal F, Basilio A, Cabello A, Díez Matas MT, García JB, González del Val A, González V, Gorrochategui J, Hernández P, Martín I, Platas G, Vicente F (1998) Endophytic fungi from plants living on gypsum soils as a source of secondary metabolites with antimicrobial activity. Mycol Res 102: $755-761$

Promputtha I, Lumyong S, Dhanasekaran V, McKenzie EHC, Hyde KD, Jeewon R (2007) A phylogenetic evaluation of whether endophytes become saprotrophs at host senescence. Microb Ecol 53:579-590

Pulimood TB, Corden JM, Bryden C, Sharples L, Nasser SM (2007) Epidemic asthma and the role of the fungal mold Alternaria alternata. J Allergy Clin Immunol 120:610-617

Purahong W, Hyde KD (2011) Effects of fungal endophytes on grass and non-grass litter decomposition rates. Fungal Divers 47:1-7

Pyrri I, Kapsanaki-Gotsi E (2007) A comparative study on the airborne fungi in Athens, Greece, by viable and non-viable sampling methods. Aerobiologia 23:3-15

Reanprayoon P, Yoonaiwong W (2011) Airborne concentrations of bacteria and fungi in Thailand border market. Aerobiologia 28:49-60

Richards M (1953) Saprophytic Cladosporium in Britain. Nature 171: 615-616

Riesen TK, Close C (1987) Endophytic fungi in propiconazole-treated and untreated barley leaves. Mycologia 79:546-552

Rodriguez RJ, White Jr JF, Arnold AE, Redman RS (2009) Fungal endophytes: diversity and functional roles. New Phytol 182: 314-330

Saikkonen K, Faeth S, Helander M, Sullivan TJ (1998) Fungal endophytes: a continuum of interactions with host plants. Ann Rev Ecol Syst 29: 319-343

Sánchez S, Bills GF, Zabalgogeazcoa I (2007) The endophytic mycobiota of the grass Dactylis glomerata. Fungal Divers 27:171-195

Sánchez S, Bills GF, Zabalgogeazcoa I (2008) Diversity and structure of the fungal endophytic assemblages from two sympatric coastal grasses. Fungal Divers 33:87-100

Sánchez S, Bills GF, Domínguez Acuña L, Zabalgogeazcoa I (2010) Endophytic mycobiota of leaves and roots of the grass Holcus lanatus. Fungal Divers 41:115-123

Sánchez S, Bills GF, Zabalgogeazcoa I (2011) Fungal species diversity in juvenile and adult leaves of Eucalyptus globulus from plantations affected by Mycosphaerella leaf disease. Ann Appl Biol 158:177187

Sánchez S, Bills GF, Herrero N, Zabalgogeazcoa I (2012) Non systemic fungal endophytes of grasses. Fungal Ecol 5:289-297 
Sautour M, Sixt N, Dalle F, L'Ollivier C, Fourquenet V, Calinon C, Paul K, Valvin S, Maurel A, Aho S, Couillault G, Cachia C, Vagner O, Cuisenier B, Caillot D, Bonnin A (2009) Profiles and seasonal distribution of airborne fungi in indoor and outdoor environments at a French hospital. Sci Total Environ 407:3766-3771

Schulz B, Boyle C (2005) The endophytic continuum. Mycol Res 109:661-686

Sen B, Asan A (2001) Airborne fungi in vegetable growing areas of Edirne, Turkey. Aerobiologia 17:6975

Shelton BG, Kirkland KH, Flanders WD, Morris GK (2002) Profiles of airborne fungi in buildings and outdoor environments in the United States. Appl Environ Microbiol 68:1743-1753

Sieber T, Riesen TK, Muller E, Fried PM (1988) Endophytic fungi in four winter wheat cultivars (Triticum aestivum L.) differing in resistance against Stagonospora nodorum. J Phytopathol 122:289-306

Sieber TN (2007). Endophytic fungi in forest trees: are they mutualists?. Fungal Biol Rev 21:75 - 89

Sieber Canavesi F, Sieber TN (1993) Successsional patterns of fungal communities in needles of European silver fir (Abies alba Mill.). New Phytol 125:149-161

Stone JK, Polishook JD, White Jr JF (2004) Endophytic fungi. In: Mueller GM, Bills GF, Foster MS (eds) Biodiversity of fungi. Inventory and monitoring methods. Elsevier Academic Press, USA, pp 241-270

Stennett PJ, BeggsPJ (2004) Alternaria spores in the atmosphere of Sydney, Australia, and relationships with meteorological factors. Int J Biometeorol 49:98-105

Strömberg C (2011) Evolution of grasses and grassland ecosystems. Annu Rev Earth PI Sci 39:517-544

Su YY, Guo LD, Hyde KD (2010) Response of endophytic fungi of Stipa grandis to experimental plant function group removal in Inner Mongolia steppe, China. Fungal Divers 43:93-101

Suerdem TB, Yildirim I (2009) Fungi in the atmospheric air of Anakkale province in Turkey. African J Biotechnol 8:4450-4458

Sun X, Guo LD, Hyde KD (2011) Community composition of endophytic fungi in Acer truncatum and their role in decomposition Fungal Divers 47:85-95

Takahashi T (1997) Airborne fungal colony forming units in outdoor and indoor environments in Yokohama, Japan. Mycopathologia 139:23-33

Thomas MR, Shattock RC (1986). Filamentous fungal associations in the phylloplane of Lolium perenne. Trans Brit Mycol Soc 87:255-268

Thomma B (2003) Alternaria spp.: from general saprophyte to specific parasite. Mol Plant Pathol 4:225236

Uddin N (2005) Estimation of aeromycoflora in jute fields. Aerobiologia 21:75-80

Ulevicius V, Peciulyte D, Lugauskas A, Andriejauskiene J (2004) Field study on changes in viability of airborne fungal propagules exposed to UV radiation. Environ Toxicol 19:437-441

Wearn JA, Sutton BC, Morley NJ, Gange AC (2012) Species and organ specificity of fungal endophytes in herbaceous grassland plants. J Ecol 100: 1085-1092 
Webster J (1956) Succession of fungi on decaying cocksfoot culms. Part I. J Ecol 44:517-544

Wirsel SGR, Leibinger W, Ernst M, Mendgen K (2001) Genetic diversity of fungi commonly associated with common reed. New Phytol 149:589-598

Wong KM, Hyde KD (2001) Diversity of fungi on six species of Gramineae and one species of Cyperaceae in Hong Kong. Mycol Res 105:1485-1491

White IR, Backhouse D (2007) Comparison of fungal endophyte communities in the invasive panicoid grass Hyparrhenia hirta and the native grass Botriochloa macra. Aust J Bot 55:178-185

Wirsel SGR, Leibinger W, Ernst M, Mendgen K (2001) Genetic diversity of fungi commonly associated with common reed. New Phytol 149:589-598

Yuan ZL, Rao LB, Chen YC, Zhang CL, Wu YG (2011) From pattern to process: species and functional diversity in fungal endophytes of Abies beshanzuensis. Fungal Biol 115:197-213

Zhou DQ, Hyde KD (2002) Fungal succession on bamboo in Hong Kong. Fungal Divers 10:213-227 
Table 1 Surveys of fungal endophytes made in thirteen grass species that were used to identify multihost and most frequent fungal taxa.

\begin{tabular}{ll}
\hline \multicolumn{1}{c}{ Grass species } & \multicolumn{1}{c}{ Reference } \\
\hline Ammophila arenaria & Sánchez et al. 2008 \\
Botriochloa macra & White and Backhouse 2007 \\
Dactylis glomerata & Sánchez et al. 2007 \\
Elymus farctus & Sánchez et al. 2008 \\
Holcus lanatus & Sánchez et al. 2010 \\
Hypharrhenia hirta & White and Backhouse 2007 \\
Hordeum vulgare & Riesen and Close 1987 \\
Oryza spp & Fisher and Petrini 1992 \\
Panicum virgatum & Kleczewski et al. 2012 \\
Phragmites australis & Wirsel et al. 2001 \\
Stipa grandis & Su et al. 2010 \\
Stipa tenacissima & Peláez et al. 1998 \\
Triticum aestivum & Sieber et al. 1988 \\
Zea mays & Fisher et al. 1992; Pan et al. 2008 \\
\hline
\end{tabular}


Table 2 Surveys of airbone fungi done in 41 urban and rural habitats, in 27 different countries. Urban habitats were inside cities and rural habitats include croplands, grasslands, forests and large city parks.

\begin{tabular}{|c|c|c|}
\hline Country & Type of habitat & Reference \\
\hline Australia & urban & Garrett et al. 1997 \\
\hline Australia & urban & Mitakakis and Guest 2001 \\
\hline Argentina & urban & Mallo et al. 2011 \\
\hline Brazil & urban & Gonzalves et al. 2010 \\
\hline Canada & rural & Li and Kendrick 1995 \\
\hline Chile & urban & Henriquez et al. 2001 \\
\hline China & rural $^{*}+$ urban & Fang et al. 2005 \\
\hline Egypt & rural $^{*}+$ urban & Awad 2005 \\
\hline Egypt & urban & Abdel Hameed et al. 2007 \\
\hline Egypt & rural & Abdul Wahid et al. 1996 \\
\hline France & urban & Sautour et al. 2009 \\
\hline Greece & urban & Pyrri and Kapsanaki-Gotsi 2007 \\
\hline India & rural & Nayar et al. 2007 \\
\hline India & rural & Uddin 2005 \\
\hline Italy & urban & Airaudi and Marchisio 1996 \\
\hline Italy & rural & Magyar et al. 2009 \\
\hline Japan & rural & Takahashi 1997 \\
\hline Jordanian & rural & Abu-Dieyeh et al. 2010 \\
\hline Kuwait & urban & Moustafa and Kamel 1976 \\
\hline Lithuania & rural & Ulevicius et al. 2004 \\
\hline Lithuania & urban & Lugauskas et al. 2003 \\
\hline Mexico & rural + urban & Calderon et al. 1997 \\
\hline Nigeria & rural & Dransfield 1966 \\
\hline Poland & urban & Kasprzyk and Worek 2006 \\
\hline Portugal & rural & Oliveira et al. 2009 \\
\hline Qatar & urban & Al Subai 2002 \\
\hline Saudi Arabia & rural + urban & Al Suwaine et al. 1999 \\
\hline Singapore & rural & Lim et al. 1998 \\
\hline Spain & rural & Muñoz et al. 2010 \\
\hline Spain & urban & Herrero et al. 2006 \\
\hline Thailand & urban & Reanprayoon and Yoonaiwong 2011 \\
\hline Turkey & rural & Sen and Asan 2001 \\
\hline Turkey & urban & Suerdem and Yildirim 2009 \\
\hline Uganda & rural & Ismail et al. 1999 \\
\hline USA & urban & Shelton et al. 2002 \\
\hline
\end{tabular}

* two different locations studied 
Fig. 1 Mean frequency of endophytic genera of grasses, indicating the mean percentage of the whole endophytic assemblage that each genus represents in its grass hosts. Numbers at the end of bars show the number of grass species, out of a total of 13 , where the occurrence of each endophyte genus was reported.

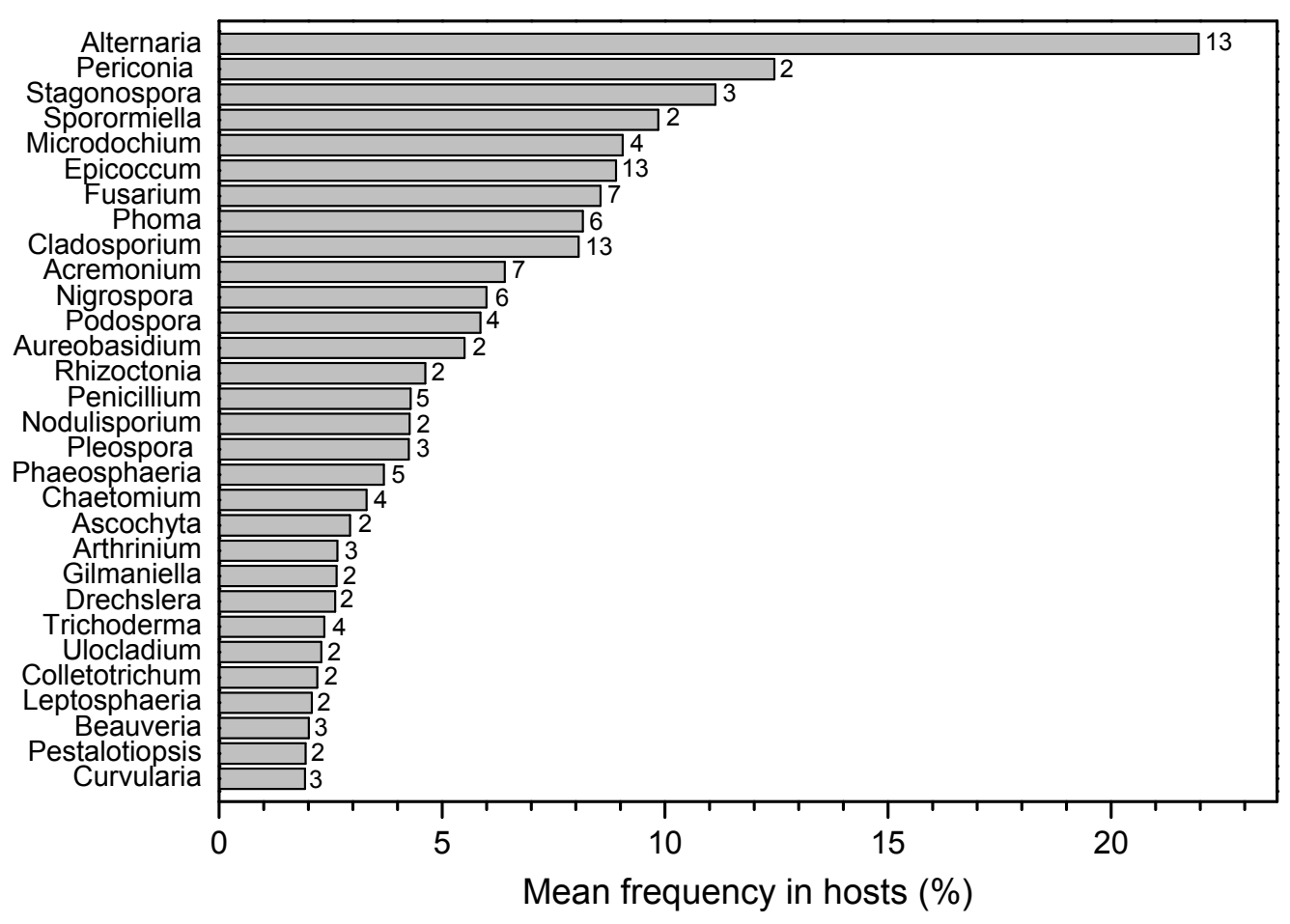


Fig. 2 Total frequency in grasses of multihost endophytic taxa. The total frequency estimates the frequency of each taxon relative to the whole set of 13 grass species considered.

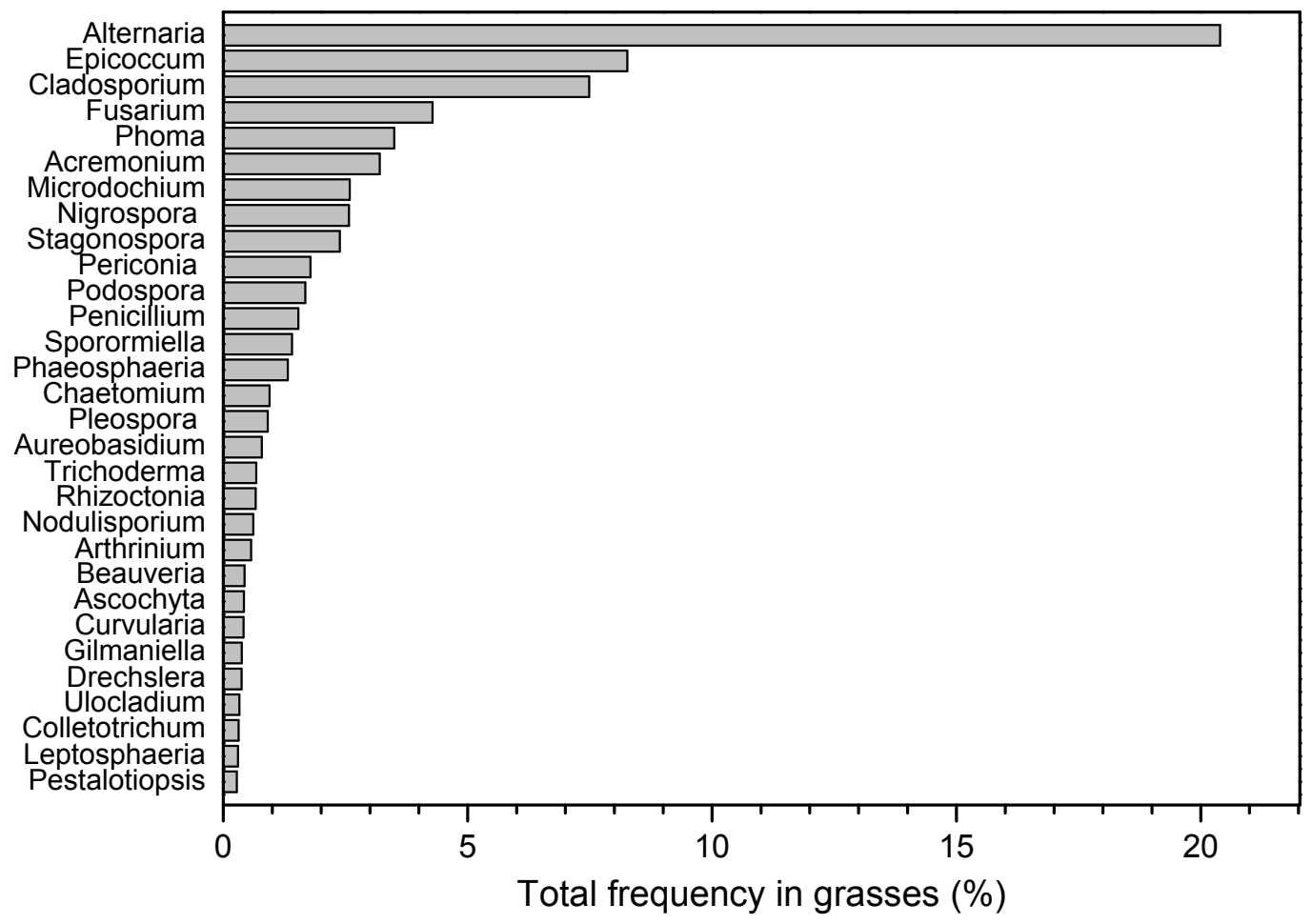


Fig. 3 Thirty five fungal genera that were identified in aerial mycobiota at two or more locations (total number of locations $=41$ ). The bars indicate the mean frequency per location, estimated as the mean proportion of the airborne mycobiota that each genus represents at the locations where it was present. The numbers at the end of the bars indicate the number of locations where each genus has been reported.

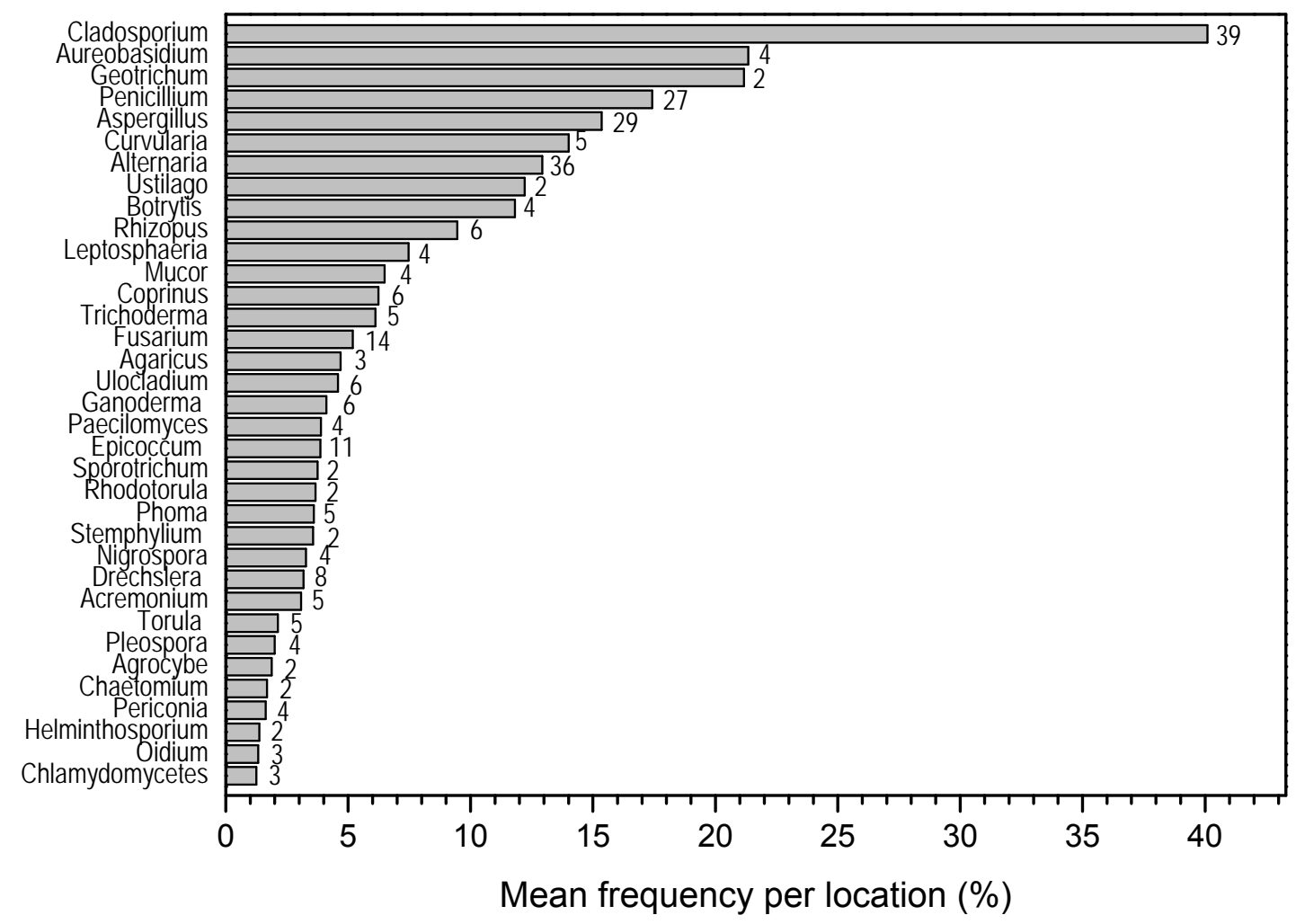


Fig. 4 Global frequency of each airborne fungal taxa. It was estimated for each genus as the sum of its frequencies at all locations where it occurred, divided by the total number of locations.

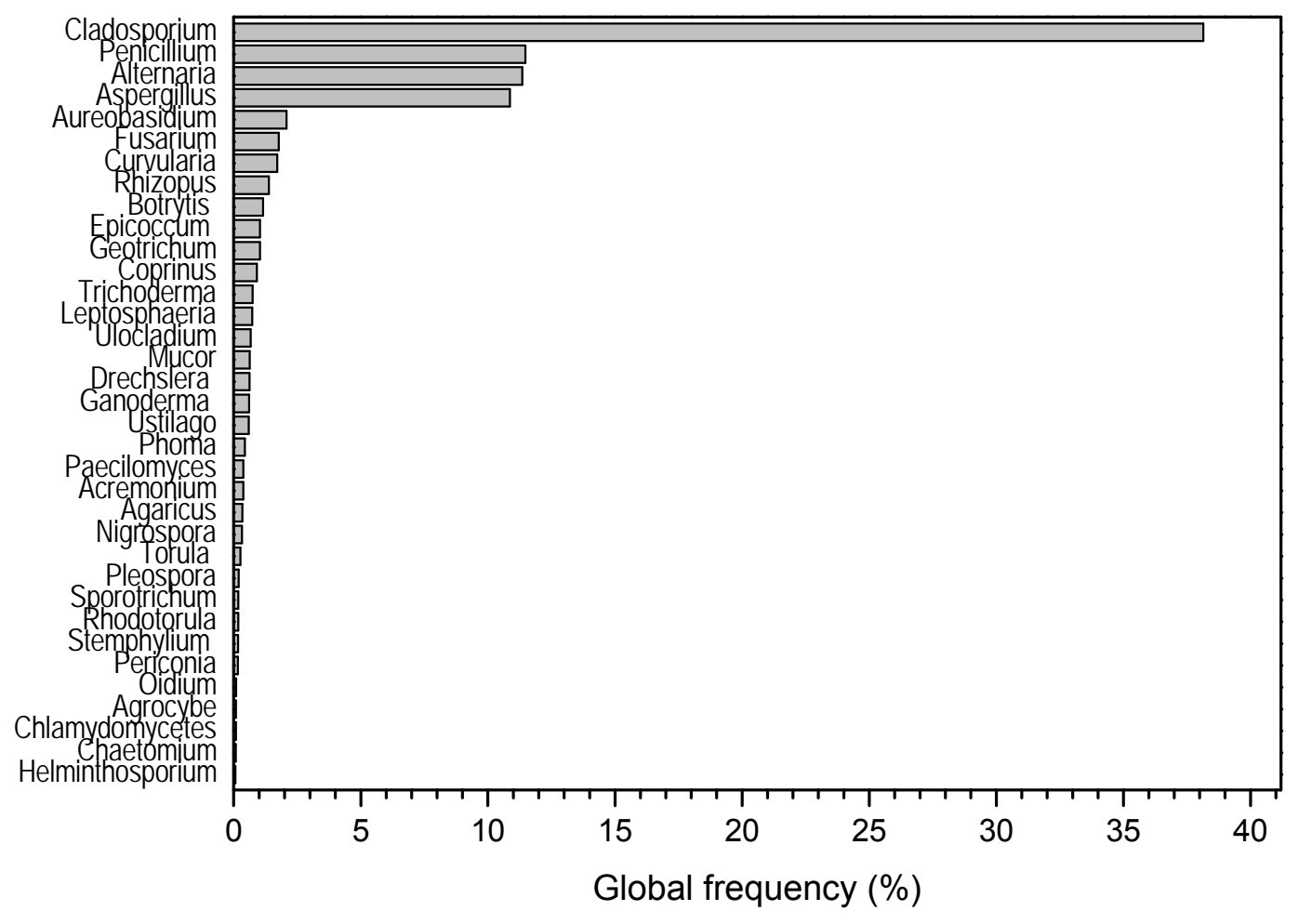


Fig. 5 Relationship between the number of grass hosts where an endophytic taxon has been reported, and the number of geographical locations where it has been reported as an airborne species. The data set $(n=17)$ contains values for taxa that have been reported as grass endophytes and airborne. The species are indicated as: ACR: Acremonium, ALT: Alternaria, CLA: Cladosporium, CHA: Chaetomium, CUR: Curvularia, DRE: Drechslera EPI: Epicoccum, FUS: Fusarium, LEP: Leptosphaeria, NIG: Nigrospora, PEN: Penicillium, PER: Periconia, PLE: Pleospora, PHO: Phoma, TRI: Trichoderma, ULO: Ulocladium.

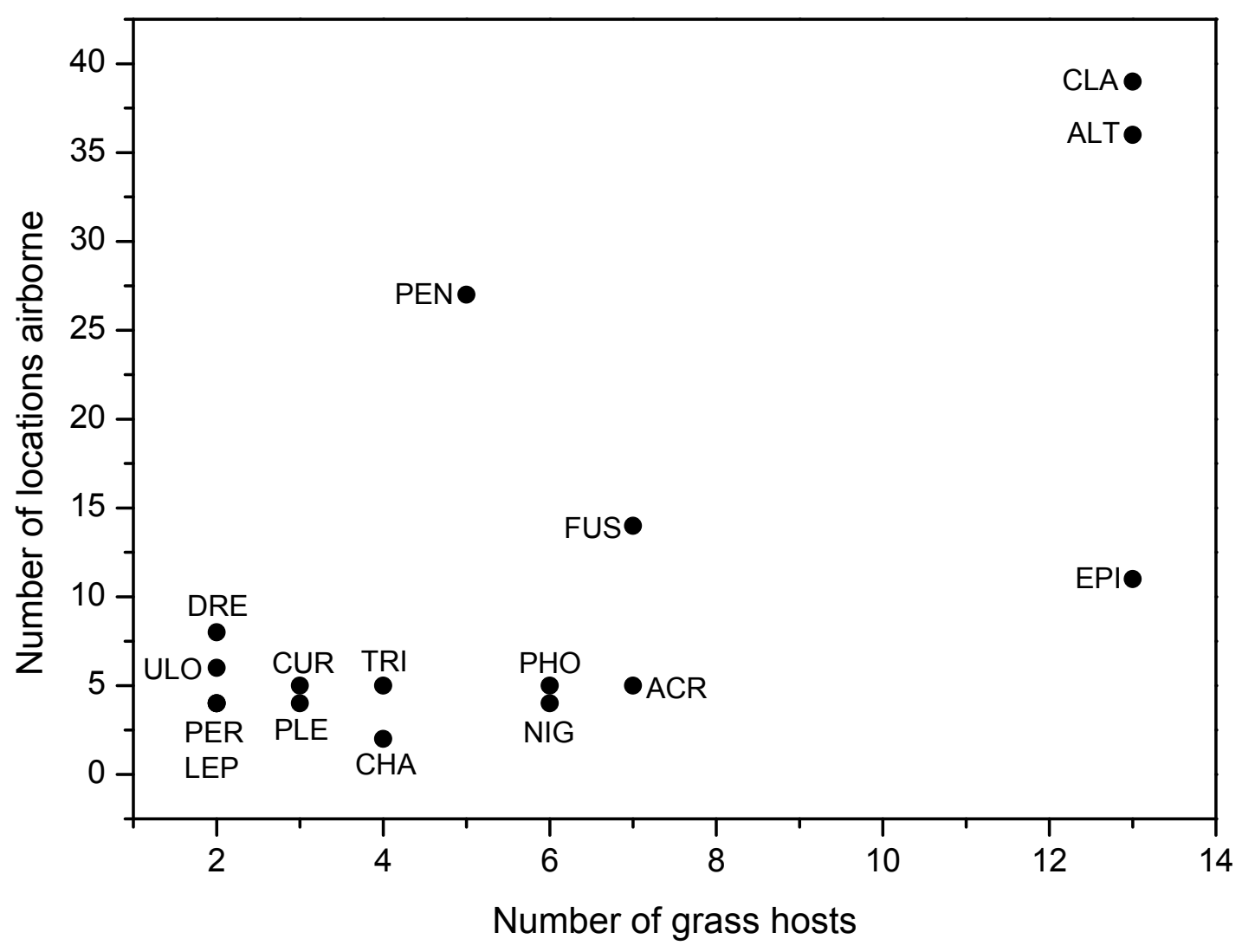


Fig. 6 A hypothetical life cycle of dominant endophytic taxa of grasses that also have been reported as common airborne fungi, such as Alternaria, Cladosporium, Epicoccum, Fusarium and Penicillium. As a result of a transition from an endophytic to a saprobic lifestyle, spores are produced on dead host tissues, and these spores become airborne.

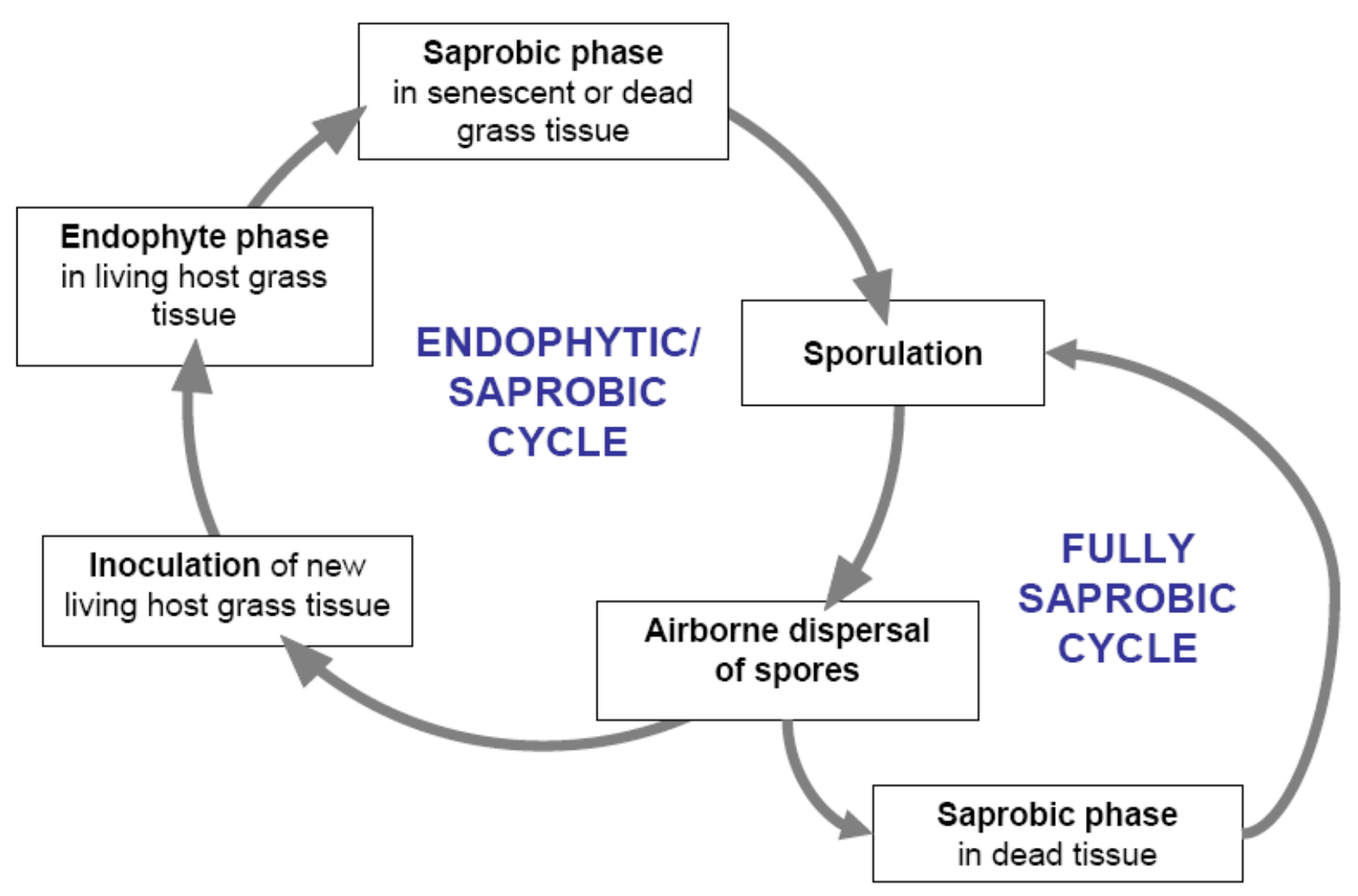


